\title{
Growth Performance of Male Line of Superior Tropical Rabbit
}

\author{
B. Brahmantiyo*, N. Pratiwi, F. Saputra, Y. C. Raharjo, \& L. H. Prasetyo \\ Indonesian Research Institute for Animal Production \\ Jalan Veteran III Ciawi - Bogor 16720, Indonesia \\ ${ }^{*}$ Corresponding author: brahmantiyo@gmail.com \\ (Received 12-08-2020; Revised 22-12-2020; Accepted 06-01-2021)
}

\begin{abstract}
New Zealand White rabbits (NN) are known as broiler rabbits that are well adapted to the Indonesian environment. HyLa rabbits are rabbits imported from China that were selected for high reproduction and growth rates. The increased productivity of $\mathrm{NN}$ rabbits was achieved by crossing to HyLa rabbits. This study was aimed to evaluate HyLa and NN rabbits' productivity and their reciprocal crosses to develop a broiler rabbit adaptive to tropical climate. Forty heads of does and 20 heads of bucks of HyLa rabbit, 30 heads of does, and 6 heads of bucks of New Zealand White rabbits (NN) were used. Reproductive performance of does (litter size at birth, litter size at weaning, mortality, and weekly does body weight) and the kit's growth performance (weekly body weight from weaning until the age of 20 weeks) was evaluated. Data were analyzed using the SAS program, FactoMineR, and factoextra package in R 4.0.0. Rabbit's growth data were periodically analyzed by the Gompertz model. At the age of 10 weeks, HyLa had a body weight of $1459.7 \pm 373.1 \mathrm{~g}$ greater than HyLa $x$ NN $(1380.1 \pm 389.9 \mathrm{~g})$, NN $x$ HyLa $(1225.7 \pm 263.4 \mathrm{~g})$, and NN $(985.0 \pm 234.4 \mathrm{~g})$. Based on the Gompertz model, NN x HyLa had an inflection point at a weight of 1,977.7 at 12 weeks. Furthermore, NN x HyLa had a better litter size than HyLa $x$ NN. NN bucks $x$ HyLa does have the potential to be developed as a superior rabbit adaptive to tropical climate.
\end{abstract}

Keywords: growth performance; HyLa rabbit; NN rabbit; crossbreeding; reciprocal

\section{INTRODUCTION}

Rabbitry has industrial-scale production in the developed countries using three-way crossbreeding to develop their broiler rabbits. Heterosis affects reproduction by crossing two breeds of rabbits, then crossbred with a male line with a rapid growth rate to produce broiler rabbits with high reproductivity and growth rate (Ragab et al., 2016). Characteristics of growth rate (before and after kindling), feed consumption, and feed conversion ratio have economic value to calculate rabbit productivity.

Traits of rabbits used to select broiler rabbits to be raised are early slaughter age, feed efficiency, with high carcass percentage, and carcass production (Paci et al., 2012). Broiler rabbits can be developed by selecting their meat production traits and conducting the crossing methods (Belabbas et al., 2019). Crossing methods are popularly used to create broiler rabbits because they can insert many characteristics.

Indonesian Research Institute for Animal Production (IRIAP) imported 40 heads of Doe and 20 heads of HyLa rabbit buck from China in 2012. HyLa rabbits were known as broiler rabbits that have good parameters of production on litter size (9.5-10.6 kits per birth), mortality by four weeks of age $(0.2 \%-4.8 \%)$, mor- tality to slaughter weight on ten weeks of age (5.0\%), and reached $2.6 \mathrm{~kg} /$ heads of body weight at slaughter. HyLa rabbits had mature weight $(6.5 \mathrm{~kg} / \mathrm{heads}-7.0 \mathrm{~kg} /$ heads) with five pairs of nipples on more than $50 \%$ of the Doe population. IRIAP also nurtured New Zealand White (NN) rabbits as a genetic resource for the breeding program. Mohammed \& Nasr (2017) describe that NN has rapid growth with an average daily gain of $21.87 \mathrm{~g}$ and lives bodyweight at the slaughter of 2,591 g.

Producing broiler rabbits by crossing using NN rabbits as a genetic source was popular. $\mathrm{NN}$ and Californian crossbred rabbits had a higher rate than $\mathrm{NN}$ and Californian as purebred on weaning weight to slaughter. The 70-day bodyweight of NN x Californian crossbred was higher than that of Californian $x$ NN. Californian rabbits had the lowest body weight. Broilerrabbit production was always developed by a three-way cross (Ragab et al., 2016), with a female line from a crossbred line selected on litter size and terminal Bucks from the male line selected on the growth rate. The growth model can be a benchmark in supporting selection for body weight. Sariyel et al. (2017) stated that the Gompertz model was a suitable model of body weight. The Gompertz model was also used in the analysis of the development of chicken (Koncagul \& Cadirci, 2010), sheep (De Paz et al., 2018), and cattle (Bahashwan 
et al., 2015). Moreover, Lenart (2012) reported that the Gompertz model was applied in the actuarial field. Goshu \& Koya (2013) also stated that Gompertz's was one of the growth curves used widely along with the other growth curves.

In order to form a crossbreed from three breeds, it is necessary to determine the male line and female line based on the results of the crossings and their reciprocities. Previous research using Hycole and NN crosses found that the Hycole (Male) x NN (Female) cross was better used as a female line (Brahmantiyo et al., 2017). Therefore in this study, the male line was determined based on growth performance. The crosses of the male line and female line that have been selected are expected to be superior tropical rabbits. This study was aimed to evaluate HyLa and NN rabbits' productivity and their reciprocal crosses as the basis for broiler rabbits' development, which has superiority to be adaptive to tropical climate.

\section{MATERIALS AND METHODS}

This experiment was approved by the animal ethics committee of the Indonesian Agency for Agricultural Research and Development, Ministry of Agriculture (Registration Number: Balitbangtan/Balitnak/ $\mathrm{Rd} / 01 / 2016)$. The number of rabbits used was 96 heads consisting of 20 Bucks (8 months old) and 40 Does (5-6 months old) of HyLa rabbits; 6 Bucks (8 months old), and 30 Does (5-6 months old) of NN rabbits. The mating process resulted in 48 mates of HyLa, 26 mates of NN, 17 mates of HyLa x NN, and 19 mates of NN x HyLa. These mates resulted in HyLa, NN, Hyla x NN, and NN x HyLa, by 378 heads, 107 heads, 161 heads, and 185 heads, respectively. The crossbreeding scheme is presented in Figure 1. The crossbreeding research was carried out at the Indonesian Research Institute for Animal Production for 18 months.

The mating with a ratio of one Buck for 4-5 Does was conducted until three parities. The Does were mated after 5-6 months old, and the Bucks were eight months of age. The Does were mated when estrus was shown by evaluating the vulva. Redden vulva showed signs of estrus. The palpation was conducted on the $12^{\text {th }}$ day after the mating to determine the success of the pregnancy. The Does who were not pregnant were remated. The nest box for pregnant Does was prepared on the $28^{\text {th }}$ day of pregnancy. The mating was immediately performed two weeks after giving birth and showing estrus. The mating system was adjusted to pedigree.

The cages were individual wire cages with the size according to the age. The cage height from the floor was $100 \mathrm{~cm}$. Each cage was equipped with a diet trough made from pottery by $15 \mathrm{~cm}$ x $12 \mathrm{~cm}$ x $60 \mathrm{~cm}$, and drinking water was provided in the nipple made from metal. The size of the Does cage was $60 \mathrm{~cm} \times 75 \mathrm{~cm} \times 40 \mathrm{~cm}$, while the Buck cage size was $75 \mathrm{~cm} \times 45 \mathrm{~cm} \times 40 \mathrm{~cm}$.

The nesting cage size was $40 \mathrm{~cm} \times 30 \mathrm{~cm} \times 25 \mathrm{~cm}$. The sawdust was used as flooring. The dams would shed their hairs that would be used as a nest for their kits. The nesting cage was cleaned when the kits reached 4-5 weeks old and were prepared for the next kits. The kits were weaned at five weeks old and maintained in a $45 \mathrm{~cm} \times 75 \mathrm{~cm} \times 45 \mathrm{~cm}$ cage made from wood.

The diet used in this study contained crude protein by $18 \%$, metabolic energy by $2500 \mathrm{kcal} / \mathrm{kg}$, and crude fiber by $14 \%$. The diet was made in the form of a pellet. The pellet was delivered in the morning and in the evening while the drinking water was provided ad libitum.

The parameters measured in this study were reproduction performance (birth litter size, weaned litter size, mortality), dam body weight (from the beginning of giving birth up to the next five weeks), and kit growth performance (weekly bodyweight from after the weaned up to 20 weeks). The weight data and reproductivity data were analyzed using SAS program with the general linear model (SAS 9.1, 2011). The Gompertz model's nonlinear growth curve based on Blasco \& Gómez (1993) proved to be the best model to describe rabbit growth.

Principle component analysis (PCA) with correlation circle was generated by FactoMineR (Husson et al., 2015) and factoextra (Kassambara \& Mundt, 2020) package in R 4.0.0 (R Core, 2020). PCA with correlation circles was made to determine the relationship between breed and crossbreed on the observed variables.

\section{RESULTS}

\section{Growth Performance of HyLa, NN, and its Reciprocal}

The kits of HyLa rabbits had faster growth rates than those of NN, HyLa $x$ NN, and NN x HyLa rabbits. The kits were weaned at the age of 5 weeks. Birth and weaning weights of HyLa kits were $57.8 \pm 11 \mathrm{~g} / \mathrm{head}$ and
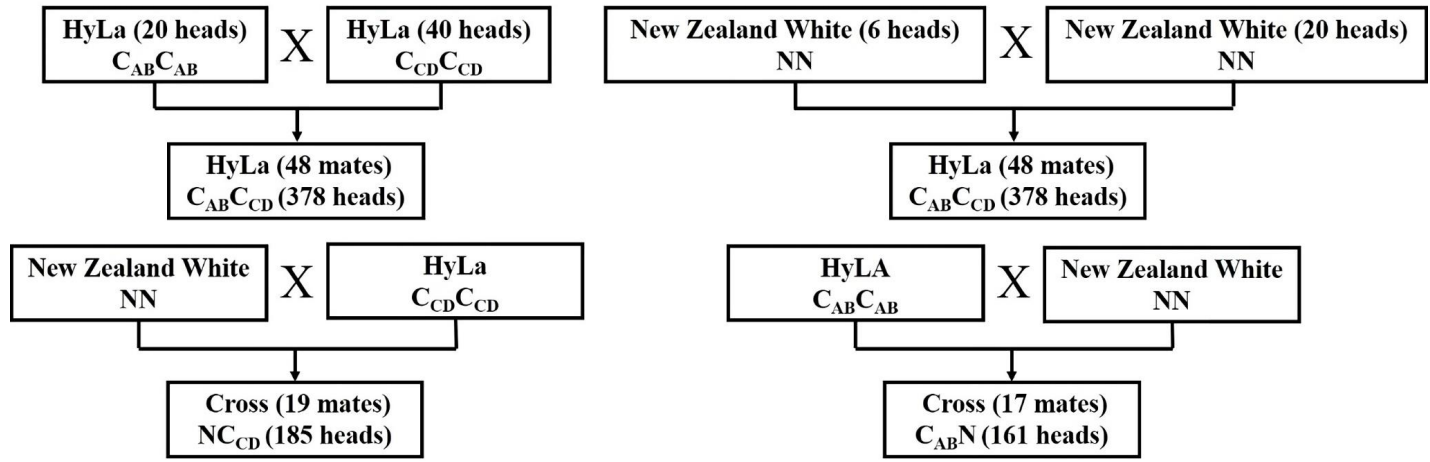

Figure 1. Diagram of the mate of HyLa dan New Zealand White rabbits 
$731.1 \pm 192.8 \mathrm{~g} /$ head, respectively. Birth and weaning weights of HyLa x NN kits were $58.6 \pm 9.2 \mathrm{~g} /$ head and $777.3 \pm 236.4 \mathrm{~g} / \mathrm{head}$, respectively. Birth and weaning weights of NN x HyLa kits were $55.3 \pm 7.4 \mathrm{~g} /$ head and $619.6 \pm 139.9 \mathrm{~g} / \mathrm{head}$, respectively. Birth and weaning weights of NN kits were $53.4 \pm 11.8 \mathrm{~g} / \mathrm{head}$ and $565.9 \pm$ $121.7 \mathrm{~g} /$ head, respectively.

The standard weight of kits at slaughtering was determined $2.0 \mathrm{~kg} / \mathrm{head}$. Similar to the faster growth rate in Hyla kits, the faster growth rates were reflected in, the shorter slaughter age to reach the standard slaughter weight of $2.0 \mathrm{~kg} / \mathrm{head}$. The HyLa kits had the mean slaughter weight of $2110.7 \pm 401.7 \mathrm{~g} /$ head at the age of 14 weeks. The HyLa $x$ NN kits had the mean slaughter weight of $2154.4 \pm 503.2 \mathrm{~g} /$ head at the age of 15 weeks. The NN x HyLa kits had the mean slaughter weight of $2145.1 \pm 400.5 \mathrm{~g} /$ head at the age of 16 weeks. The NN kits had the mean slaughter weight of $2027.7 \pm 251.3 \mathrm{~g} /$ head at the age of 17 weeks. The growth of HyLa, NN, and its reciprocal kits are presented in Table 1. Based on PCA results with correlation circles, HyLa and HyLa $x$ NN kits had the best bodyweight performances (Figure 2). This can be concluded that HyLa must be used as a male line for high bodyweight.

\section{Growth Curve Estimation}

Growth curve equation to estimate the growth rate of HyLa, NN, and their reciprocals (HyLa x NN and NN $x$ HyLa) used Gompertz models as follows: $\mathrm{Y}=4280.83 \exp (-3.51 \exp -0.12 \mathrm{t})$ for HyLa $\mathrm{Y}=3586.50 \exp (-3.37 \exp -0.12 \mathrm{t})$ for HyLa $x \mathrm{NN}$

$\mathrm{Y}=4308.02 \exp (-3.75 \exp -0.11 \mathrm{t})$ for NN x HyLa

$\mathrm{Y}=4278.58 \exp (-3.71 \exp -0.09 \mathrm{t})$ for $\mathrm{NN}$

These equations showed the growth curve graph for each HyLa HyLa x NN, NN x HyLa and NN kits might be made. The non-linear growth curve of the Gompertz model was presented in Figure 3. It showed that the growth rates of crossbred kits (HyLa $x \mathrm{NN}$ and $\mathrm{NN} \times \mathrm{HyLa}$ ) were lower than those of HyLa kits but higher than those of NN kits. The Gompertz model was also used to estimate the inflection point of bodyweight and age of the kits, as was shown in Table 2.

The inflection point of bodyweight was a point where the animal experiences a decrease in growth rate at the time unit of the inflection point of age or when the bodyweight reached its puberty period. The HyLa, $\mathrm{NN}$, and their reciprocals kits were interesting to be observed. The growth rate of kits of the HyLa $x$ NN and $\mathrm{NN} x$ HyLa rabbits reached the inflection point of age, on which both elders were influenced. The inflection point of HyLa by 10.5 weeks decreased up to 10.1 weeks after its Buck mated with Doe NN (HyLa x NN), while Doe mated with Buck NN (NN x HyLa) increased into 12.0 weeks, and the $\mathrm{NN}$ itself had an age inflection point by 14.6 weeks.

\section{Performance of Does}

In this study, evaluation of pure breed (HyLa and $\mathrm{NN}$ ) and crossing (reciprocal of HyLa and $\mathrm{NN}$ ) was done to develop broiler rabbits having optimum pro-

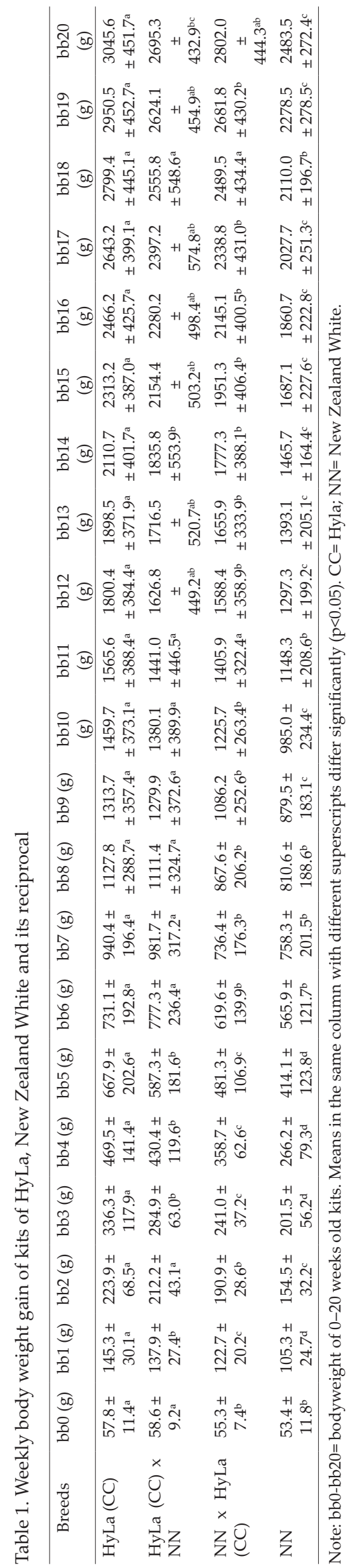




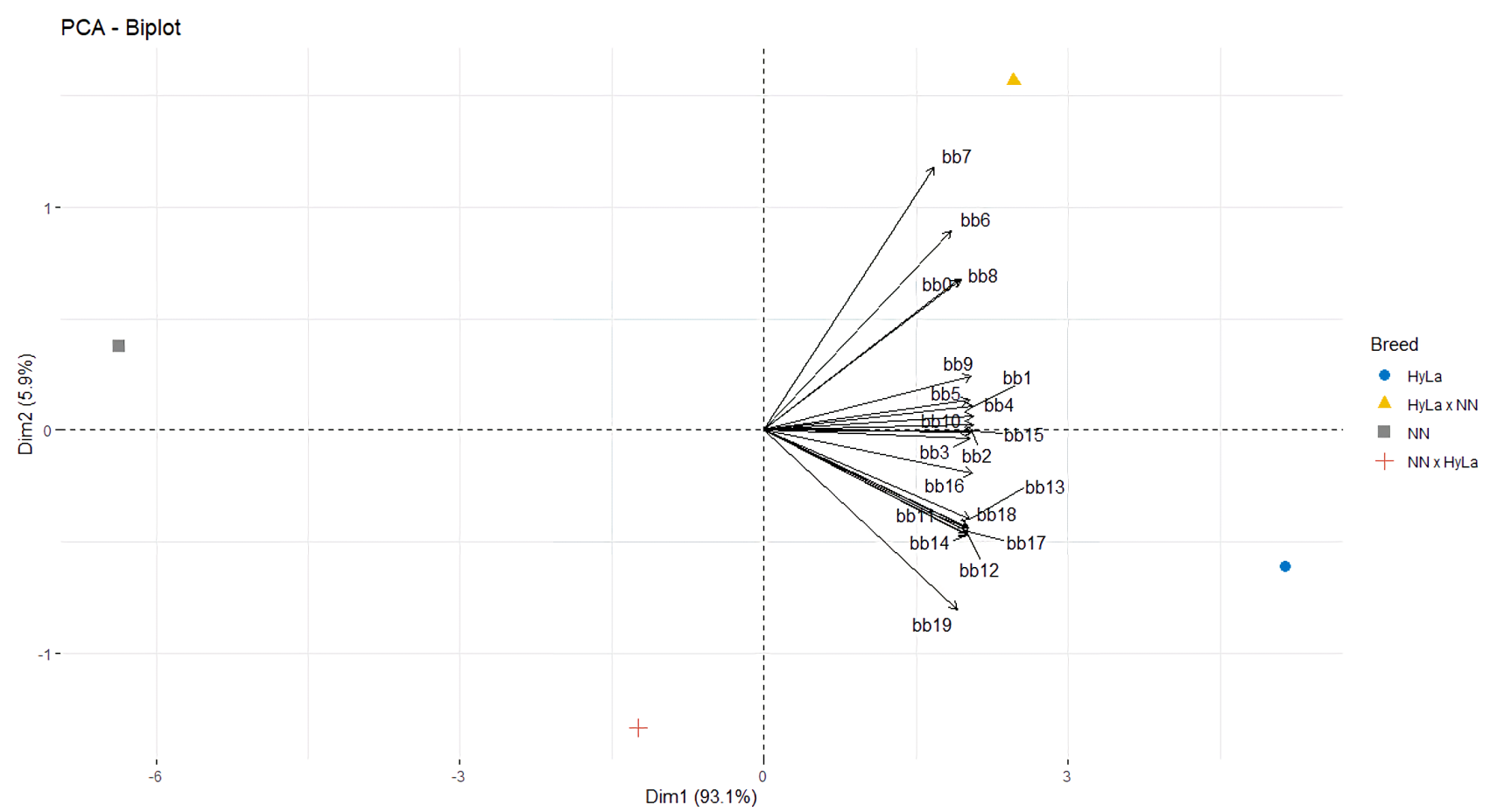

Figure 2. Principle component analysis with correlation circle based on weekly body weight gain of kits. NN= New Zealand White; bb0-bb20= bodyweight of $0-20$ weeks old kits.

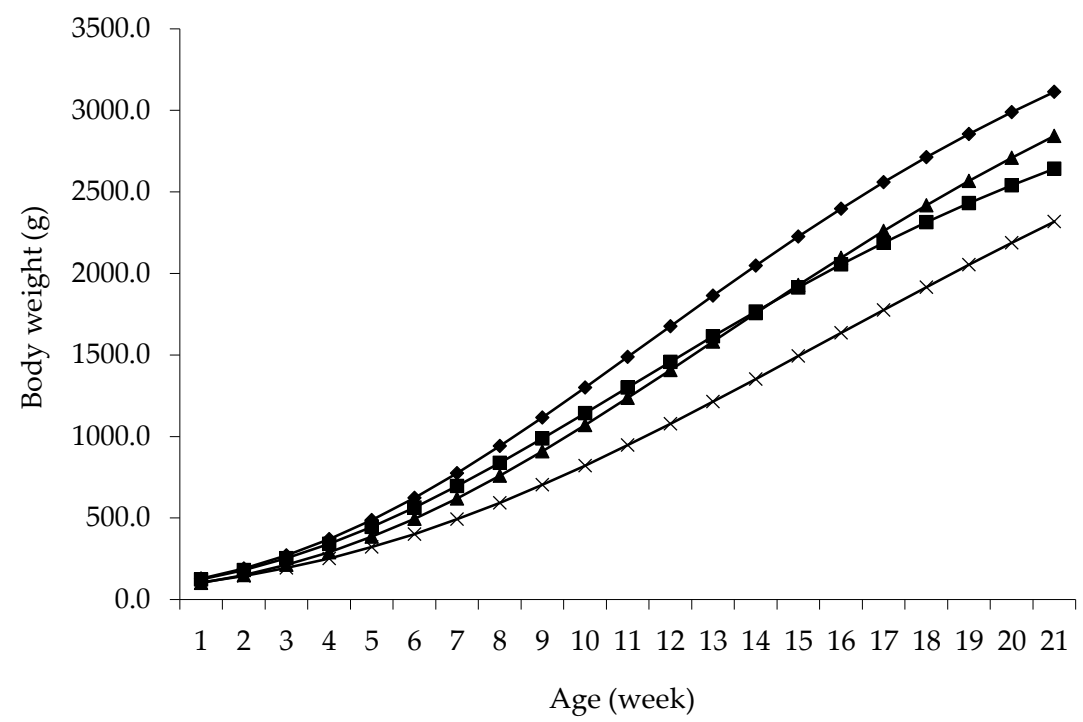

Figure 3. Graph of growth curve estimation of Gompertz model (-»-, CC; ---, CN; $-\mathbf{\Delta -}, \mathrm{NC} ;-x-$, NN). HyLa= CC; New Zealand White= NN.

Table 2. Estimation of the inflection point of body weight and age of HyLa, New Zealand White, and it's reciprocal

\begin{tabular}{lcc}
\hline Breeds & $\begin{array}{c}\text { Inflection point of } \\
\text { body weight }(\mathrm{g})\end{array}$ & $\begin{array}{c}\text { Inflection point of } \\
\text { age (week) }\end{array}$ \\
\hline HyLa & 1965.2 & 10.5 \\
HyLa x NN & 1646.5 & 10.1 \\
NN x HyLa & 1977.7 & 12.0 \\
NN & 1964.2 & 14.6 \\
\hline
\end{tabular}

Note: $\mathrm{NN}=$ New Zealand White. ductivities in humid tropical countries like Indonesia. The performances of the Does of HyLa, NN, and their reciprocals were presented in Table 3. PCA with correlation circle showed that NN x HyLa Does have good performance in litter size (Figure 4). In contrast, HyLa x NN Does have a smaller litter size with the lowest mortality.

The interaction between genetics and environment influenced the mortality of kits. High mortality in this period was apparently due to the environmental effect (climate, wind, and ambient temperature), aeration, and hygiene inside the cage, and its surroundings, causing stress to the kits. Environmental hygiene was a crucial 
factor influencing the mortality of kits in this study. The mortality in this study was highly caused by diarrhea and mastitis. Rabbit rearing needed hygiene, sanitation, smooth airflow, and appropriate treatment highly.

\section{DISCUSSION}

\section{Growth Performance of HyLa, NN, and its Reciprocal}

We found that crossing of HyLa with New Zealand White (NN) rabbit resulted in an earlier age of inflection point compared to New Zealand White (NN). This research found a positive effect of heterosis caused by HyLa. Maj et al. (2009) reported that crossing of California (CAL) with New Zealand White (NN) rabbit resulted in crossbreds having earlier slaughter age compared to its elder, i.e., $97 \pm 14$ days in $N N \times N N$, $105 \pm 17$ days in CAL x CAL, $96 \pm 13$ days in CAL $\times$ NN,

Table 3. Does performances of HyLa, New Zealand White, and its reciprocal

\begin{tabular}{lccc}
\hline Breeds & $\begin{array}{c}\text { LS birth } \\
\text { (heads) }\end{array}$ & $\begin{array}{c}\text { LS wean } \\
\text { (heads) }\end{array}$ & $\begin{array}{c}\text { Mortality } \\
(\%)\end{array}$ \\
\hline $\begin{array}{l}\text { HyLa (CC) }(48 \\
\text { heads) }\end{array}$ & $8.1 \pm 2.4^{\mathrm{a}}$ & $5.8 \pm 1.7^{\mathrm{a}}$ & $31.2 \pm 22.1^{\mathrm{a}}$ \\
$\begin{array}{l}\text { HyLa (CC) } \times \mathrm{NN} \\
(17 \text { heads) }\end{array}$ & $5.9 \pm 1.8^{\mathrm{a}}$ & $4.8 \pm 1.4^{\mathrm{a}}$ & $23.1 \pm 21.8^{\mathrm{a}}$ \\
$\begin{array}{l}\text { NN } \times \text { HyLa (CC) } \\
(19 \text { heads) }\end{array}$ & $8.5 \pm 1.7^{\mathrm{a}}$ & $6.5 \pm 1.3^{\mathrm{a}}$ & $27.2 \pm 13.9^{\mathrm{a}}$ \\
NN (26 heads) & $7.3 \pm 1.9^{\mathrm{a}}$ & $5.5 \pm 2.3^{\mathrm{a}}$ & $34.6 \pm 21.7^{\mathrm{a}}$ \\
\hline
\end{tabular}

Note: Means in the same column with different superscripts differ significantly $(p<0.05)$. NN= New Zealand White. and $94 \pm 12$ days in NN x CAL. Brahmantiyo et al. (2017) reported that crossing of HyCole (imported rabbit from France) with $\mathrm{NN}$ rabbits showed that HyCole $\left(\mathrm{P}_{\mathrm{A}} \mathrm{P}_{\mathrm{B}}\right)$ reached the slaughter weight of $2,111.9 \pm 462.3 \mathrm{~g} /$ head at the age of 14 weeks old, while the HyCole $x$ NN rabbit reached the slaughter weight of $2 \mathrm{~kg}$ at the age of 16 weeks, and the NN x HyLa and NN rabbits reached the slaughter age at 17 weeks old with the slaughter weights of $2,086.0 \pm 511.9 \mathrm{~g} /$ head and 2,027.7 $\pm 251.3 \mathrm{~g} / \mathrm{head}$, respectively.

Goshu \& Koya (2013) described that the inflection point was a trait of growth curves such as Richard Model, Von Bertalanffy, Brondy, logistic, and Gompertz. The inflection point of growth curve was a curve where the growth rate reached a maximum value and showed a crucial physical interpretation (Goshu \& Koya, 2013). The inflection point was related to age and body weight. On this point, the auto acceleration step was replaced by the auto retardation step (Setiaji et al., 2013). The inflection points of bodyweights of the HyLa, NN, HyLa x NN, and NN x HyLa were 1,965.2 g/head, 1,964.2 g/ head, 1,646.5 g/head, and 1,977.7 g/head, respectively. This inflection point was highly influenced by breed. Brahmantiyo \& Raharjo (2011) reported that Rex and Satin's rabbits reached adult age by 8.6 weeks and 10.3 weeks, respectively. The inflection point in the growth curve had high statistical attractiveness (Goshu \& Koya, 2013).

Brahmantiyo \& Raharjo (2011) reported that the change of growth curve caused by the selection of weaning weight of Satin rabbit (SS) increased its puberty weight from $1,301.12 \mathrm{~g}$ to $1,451.05 \mathrm{~g}$ at the same age of 10.3 weeks. In contrast, the selection of weaning weight

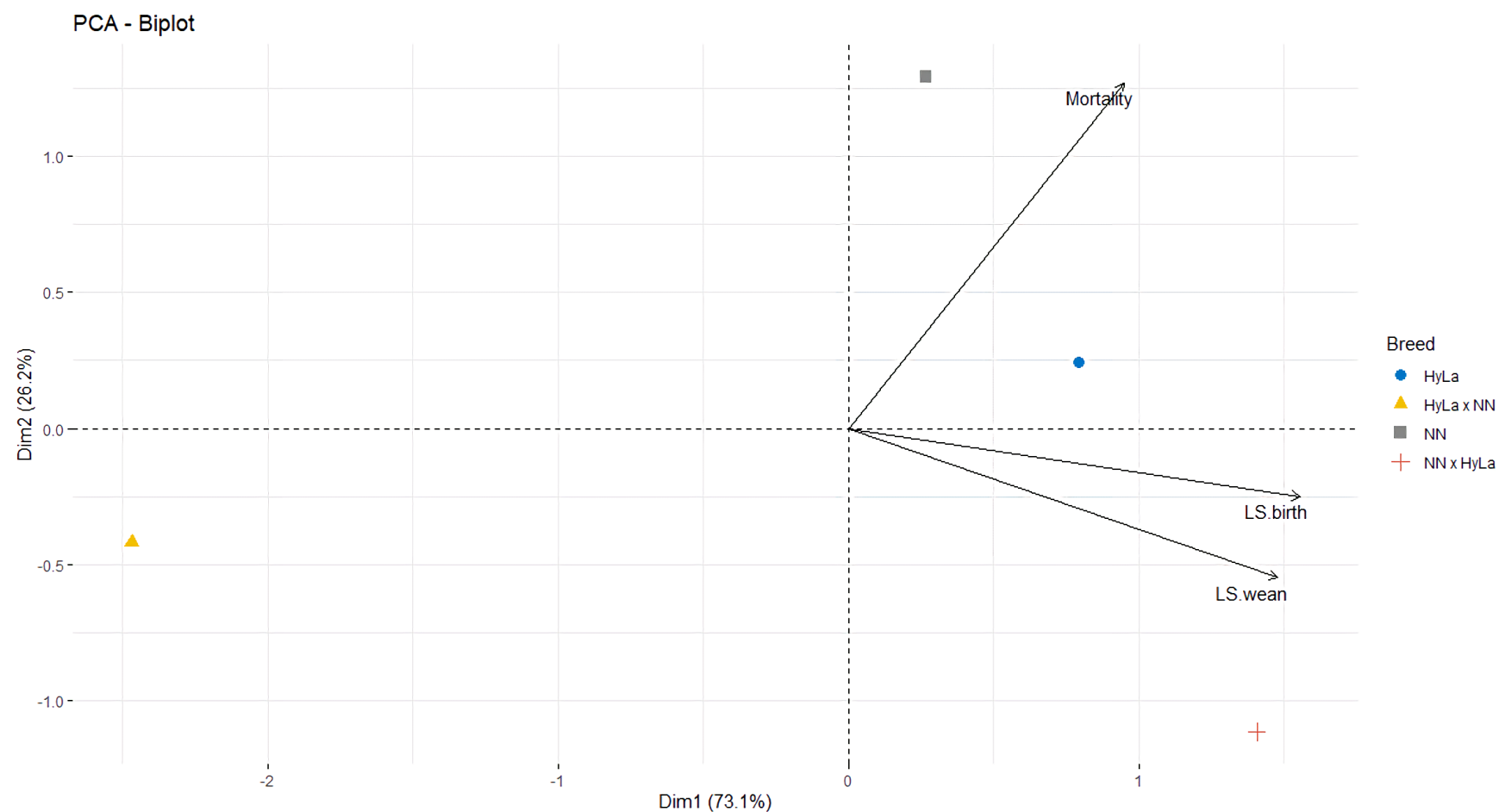

Figure 4. Principle component analysis with correlation circle based on does performance. NN= New Zealand White; bb0-bb20= bodyweight of $0-20$ weeks old kits. 
of Rex rabbit (RR) and Reza rabbit (RS) increased their puberty weights and time from 1,135.87 $\mathrm{g}$ at 8.6 weeks of age to $1,446.22 \mathrm{~g}$ at 10.1 weeks of age of RR and from $1,080.79 \mathrm{~g}$ on 8.0 weeks of age to $1,571.86 \mathrm{~g}$ on 10.5 weeks of age of RS. Brahmantiyo et al. (2017) reported HyCole imported rabbits from France were crossed with New Zealand White, and their reciprocals had influenced their puberty weights and ages. Larzul \& De Rochambeau (2004) stated that selection on growth rate would decrease adult age when the animal was slaughtered on the appointed weight (constant), which was reached in a shorter time. They also stated that the selection of a growth rate influenced the growth path of the rabbit. Ouyed \& Brun (2008) revealed that the formation of broiler rabbits should follow the three-way cross with the dam of crossbred Californian $x$ New Zealand White (CAL $x$ NN), which was mated with the sire Giant Blanc du Bouscat (GB). Then, the evaluation result of productivity of the HyLa and HyLa $x$ NN and NN $x$ HyLa with NN might have been a basis of broiler rabbit formation by adding the $3^{\text {rd }}$ HyCole breed.

\section{Does Performance of HyLa, NN, and its Reciprocal}

In this study, the litter size of HyLa was $8.1 \pm 2.4$ heads, and this result was lower than the result reported by Lenoir et al. (2012) that litter size was more than nine kits. Mortalities of kits of the HyLa, HyLa x NN, NN x HyLa and NN rabbits were $31.2 \pm 22.1 \%, 23.1 \pm 21.8 \%, 27.2$ $\pm 13.9 \%$, and $34.6 \pm 21.7 \%$, respectively. Olowofeso et al. (2012) reported that the mortalities of kits in the crossed rex (RX), Flemish Giant (GF), and Chinchilla $(\mathrm{CH})$ rabbits reared in Southwest Nigeria were $18.26 \%(\mathrm{CH} \mathrm{x}$ GF) to $30.03 \%$ (GF x RX). Rabbit mortality rates in tropical countries are higher due to a high ambient temperature and humidity causing heat stress. According to our experience in the field, diarrhea is a disease with high mortality in rabbits. Jimoh \& Ewuola (2018) described that rabbits raised in the tropical region are prone to heat stress due to the high ambient temperature. Appropriate management is required to monitor the mating, earlier disease outbreak, patience and attention, and much knowledge about the rabbit.

\section{CONCLUSION}

HyLa rabbits which were developed in Indonesia, have a better productive performance of Does (litter size at birth, litter size at wean, mortality, and weekly does bodyweight) and the kit's growth performance (weekly body weight from weaning until the age of 20 weeks) than NN rabbits. The crossing of NN bucks with HyLa does have the potential to be developed as genetic resources as the male line for forming superior rabbit adaptive to the tropical condition based on litter size and growth performance.

\section{CONFLICT OF INTEREST}

We certify that there is no conflict of interest with any financial, personal, or other relationship with other people or organization related to the material discussed in the manuscript.

\section{REFERENCES}

Bahashwan, S., A. S. Alrawas, S. Alfadli, \& S. E. Johnson. 2015. Dhofari cattle growth curve prediction by different nonlinear model functions. Livest. Res. Rural. Dev. 27.

Belabbas, R., M. De La Luz García, H. Ainbaziz, N. Benali, A. Berbar, Z. Boumahdi, \& M. J. Argente. 2019. Growth performances, carcass traits, meat quality, and blood metabolic parameters in rabbits of local Algerian population and synthetic line. Vet. World. 12:55-62. https://doi. org/10.14202/vetworld.2019.55-62

Blasco, A., \& E. Gómez. 1993. A note on growth curves of rabbit lines selected on growth rate or litter size. Anim. Prod. 57:332-334. https://doi.org/10.1017/S000335610000698X

Brahmantiyo, B., \& Y. C. Raharjo. 2011. Peningkatan produktivitas kelinci Rex, Satin dan persilangannya melalui seleksi. Jurnal Ilmu Ternak dan Veteriner. 16:243-252.

Brahmantiyo, B., Y. C. Raharjo, \& L. H. Prasetyo. 2017. Production performance of HyCole, New Zealand White Rabbits and its reciprocal. Jurnal Ilmu Ternak Dan Veteriner. 22:16-23. https://doi.org/10.14334/jitv.v22i1.1590

De Paz, C. C. P., G. C. Venturini, E. Contini, R. L. D. Da Costa, L. P. Lameirinha, \& C. R. Quirino. 2018. Nonlinear models of brazilian sheep in adjustment of growth curves. Czech. J. Anim. Sci. 63:331-338. https://doi. org $/ 10.17221 / 87 / 2017-$ CJAS

Goshu, A. T., \& P. R. Koya. 2013. Derivation of inflection points of nonlinear regression curves - implications to statistics. Am. J. Theor. Appl. Stat. 2:268-272. https://doi. org/10.11648/j.ajtas.20130206.25

Husson, F., J. Josse, S. Le, \& J. Mazet. 2015. FactoMineR: Multivariate exploratory data analysis and data mining (Version 1.31.4). https://cran.r-project.org/web/packages/ FactoMineR [10 December 2015].

Jimoh, O. A., \& E. O. Ewuola. 2018. Thermophysiological traits in four exotic breeds of rabbit at least temperature-humidity index in humid tropics. J. Basic Appl. Zool. 79:1-6. https://doi.org/10.1186/s41936-018-0031-9

Kassambara, A., \& F. Mundt. 2020. Factoextra: Extract and Visualize the Results of Multivariate Data Analyses (Version 1.0.7). https://cran.r-project.org/web/packages/ factoextra [18 December 2020]

Koncagul, S., \& S. Cadirci. 2010. Analysis of growth of broilers with restricting and unrestricting initial body weight in Gompertz-Laird model in different environments. Ital. J. Anim. Sci. 9:e5. https://doi.org/10.4081/ijas.2010.e5

Larzul, C., \& H. De Rochambeau. 2004. Comparison of ten rabbit lines of terminal bucks for growth, feed efficiency and carcass traits. Anim. Res. 53:535-545. https://doi. org/10.1051/animres:2004032

Lenart, A. 2012. The Gompertz distribution and Maximum Likelihood Estimation of its parameters - a revision. MPDIR Working Papers. p. 1-19.

Lenoir, G., H. Garreau, \& M. Banville. 2012. Estimation of genetic parameters and trends for birth weight criteria in HyCole d line. Proceedings 10 Th World Rabbit Congress. p. 183-187.

Maj, D., J. Bieniek, P. Lapa, \& L. Sternstein. 2009. The effect of crossing New Zealand White with Californian rabbits on growth and slaughter traits. Arch. Anim. Breed. 52:205211. https://doi.org/10.5194/aab-52-205-2009

Mohammed, H. \& M. Nasr. 2017. Growth performance, carcass traits, behaviour and welfare of New Zealand White rabbits housed in different enriched cages. Anim. Prod. Sci. 57:1759. https://doi.org/10.1071/AN15865 
Olowofeso, B. O., A. J. Adejuwon, \& V. A. Ademokoya. 2012. Breeding and productive performance of three breeds of rabbit in South-West Nigeria. Glob. J. Sci. Front. Res. 12:35-38.

Ouyed, A., \& J. M. Brun. 2008. Comparison of growth performans and carcass qualities of crossbred rabbits from four sire lines in Quebec. $9^{\text {th }}$ World Rabbit Congress. p.189-193.

Paci, G., Cecchi, F., Preziuso, G., Ciampolini, R., \& D'Agata, M. 2012. Carcass traits and meat quality of two different rabbit genotypes. Ital. J. Anim. Sci. 11:e45. https://doi. org/10.4081/ijas.2012.e45

R Core Team. 2020. R: A Language and Environment for Statistical Computing. $\mathrm{R}$ Foundation for Statistical Computing. https://www.r-project.org/
Ragab, M., J. P. Sánchez, C. Mínguez, \& M. Baselga. 2016. Crossbreeding effects on rabbit reproduction from four maternal lines of rabbits. Anim. 10:1086-1092. https://doi. org/10.1017/S1751731115002918

Sariyel, V., A. Aygun, \& I. Keskin. 2017. Comparison of growth curve models in partridge. Poult. Sci. 96:1635-1640. https:// doi.org/10.3382/ps/pew472

SAS 9.1. 2011. SQL Procedure User's Guide (9.1). SAS Institute. Setiaji, A., S. Sutopo, \& E. Kurnianto. 2013. Growth analysis in rabbit using gompertz non-linear model. J. Indones. Trop. Anim. Agric. 38:92-97. https://doi.org/10.14710/ jitaa.38.2.92-97 